\title{
Klinik Depresyon Hastalarında Dini İnanç ve Uygulamaların Depresyon ve Umutsuzlukla İlişkisi*
}

PATRICIA E. MURPHY, JOSEPH W. CIARROCCHI, RALPH L. PIEDMONT, SHARON CHESTON, MARK PEYROT \& GEORGE FITCHETT ÇEVIREN: UZM.PSK. ÖZLEM GÜLER

e-posta: aramissis@hotmail.com

\begin{abstract}
Religious belief and practices have been associated with lower levels of depression in persons dealing with stressful situations. In this study, researchers examined this relationship in 271 persons diagnosed with clinical depression, It was hypothesized that religious belief and practices would be associated with lower depression and that this relationship would be mediated by hopelessness. Religious belief, but not religious behavior, was a significant predictor of lower levels of hopelessness and depression beyond demographic variables. Through the relation of religious belief to lower levels of hopelessness, religious belief was indirectly related to less depression. There was also a small direct positive association of belief with depression, pointing to the complexity of the role belief plays for religious persons. Further study is needed for a better understanding of different ways religion affects depressed persons.
\end{abstract}

Dinin, bir insanın iyi olma haline katkıda bulunduğuna dair farkındalık artmaktadır $^{1}$. Dinin, stresli yaşam olaylarıyla başa çıkmaya nasıl yardımcı olduğunu açıklamaya çalışan araştırmacılar, dini davranış ve inançları araştırmaktadır. Çalışmalar, sık sık ibadet eden bireylerin, nadir olarak ibadete katılanlardan daha az depresif olduklarını göstermiştir ${ }^{2}$. Bu durum, ibade-

* Bu makale, Journal of Consulting and Clinical Psychology, (2000,Vol.68,No.6, 1102-1106) dergisinde yayınlanmıştır.

1 Myers, D. G. (2000). The funds, friends, and faith of happy people. American Psychologist, 55, 56-67.

2 Idler, E. L. (1987). Religious involvement and the health of the elderly: Some hypotheses and an initial test. Social Forces, 66, 226-238; Idler, E. L., \& Kasl, S. V. (1992). Religion, disability, depression, and the timing of death. The American Journal of Sociology, 97, 1052-1079; 
te katılmanın faydalarının, kısmen, sosyal destek ile bağlantılı olduğunu göstermektedir ${ }^{3}$. Yaşlı örneklemlerde, dini davranışın bu yönü, ibadetlere katılmak için gereken fiziksel yeterliliklerle karıştırılabilir ${ }^{4}$ İkinci bir dini davranış olarak bireysel dua ve ibadetlerle depresyon arasında pozitif yönde bir korelasyon bulunmuştur. Bireysel uygulamalar ile olumsuz yaşam olayları arasındaki bağlantı, kişisel dini uygulamaların bir başa çıkma yolu olarak kullanıldığına işaret etmektedir ${ }^{5}$.

Yapılan bir araştırmada, yas tutan ebeveynlerde, dini inancın düşük depresyonla ilişkili olduğu gösterilmiştir ${ }^{6}$. Bu sonuç, bireylerin, olumsuz olaylarda bir anlam bulabilmeleri için dinin bireylere bilişsel bir yapı temin ederek daha az depresyon yaşanmasını sağlaması ile bağlantılı gibi görünmektedir?

Yine de bu güne kadar hiç kimse dinin, tek epizod olarak ya da kronik bir bozukluk olarak klinik depresyon tanısı almış kişiler için oynadığı rolü tam olarak açıklayamamıştır. Depresyon teorileri, umutsuzluğu, depresyonun temel özelliklerinden biri olarak tanımlamıştır ${ }^{8}$. Beck ${ }^{9}$, depresyonun

Koenig, H. G. (1995). Religion and older men in prison. International Journal of Geriatric Psychiatry, 10, 219-230; Koenig, H. G., Hays, J. C., George, L. K., Blazer, D. G., Larson, D. B., \& Landerman, L. U (1997). Modeling the cross-sectional relationships between religion, physical health, social support, and depressive symptoms. The American Journal of Geriatric Psychiatry, 5, 131-144; Nolen-Hoeksema, S., \& Larson, J. (1999). Coping with loss. Mahaw, NJ: Erlbaum; Pressman, P., Lyons, J. S., Larson, D. B., \& Strain, J. J. (1990). Religious belief, depression, and ambulation status in elderly women with broken hips. American Journal of Psychiatry, 147, 758-760; Wright, L. S., Frost, C. J., \& Wisecarver, S. J. (1993). Church attendance, meaningfulness of religion, and depressive symptomatology among adolescents. Journal of Youth and Adolescence, 22, 559-568.

3 Mclntosh, D. N., Silver, R. C., \& Wortman, C. B. (1993). Religion's role in adjustment to a negative life event: Coping with the loss of a child. Journal of Personality and Social Psychology, 65, 812-821; Sherkat, D. E., \& Reed, M. D. (1992). The effects of religion and social support on self-esteem and depression among the suddenly bereaved. Social Indicators Research, 26, 259-275.

4 Idler, E. L. (1987). A.g.e.; Levin, J. S., \& Vanderpool, H. Y. (1987). Is frequent religious attendance really conducive to better health? Toward an epidemiology of religion. Social Science and Medicine, 24, 589-600.

5 Ellison, C. G. (1991). Race, religious involvement and depressive symptomatology in a southeastern U.S. community. Social Science and Medicine, 40, 1561-1572.

6 Maton, K. I. (1989). The stress-buffering role of spiritual support: Crosssectional and prospective investigations. Journal for the Scientific Study of Religion, 28, 310-323; Mclntosh, D. N., Silver, R. C., \& Wortman, C. B. (1993). A.g.e.

7 Blaine, B., \& Crocker, J. (1995). Religiousness, race, and psychological well-being: Exploring social psychological mediators. Personality and Social Psychology Bulletin, 21, 1031-1041; Mclntosh, D. N., Silver, R. C., \& Wortman, C. B. (1993). A.g.e.

8 Beck, A. T. (1967). Depression: Clinical, experimental and theoretical aspects. New York: Harper \& Row.; Beck, A. T., Rush, A. J., Shaw, B. F., \& Emery, G. (1979). Cognitive therapy of depression. New York: Guilford Press; Brown, G. W., \& Harris, T. (1978). Social origins of 
bütünleyici bir parçası olarak benlik, dünya ve gelecek hakkındaki olumsuz düşünceler üçlüsünü ileri sürmüştür. Olumsuz bir olaya tepki olarak ortaya çıkan bazı depresyon durumlarında bu olumsuz düşünceleri içeren şemanın, nedensel bir rol oynayabileceğini öne sürmektedir.

Depresyonun umutsuzluk teorisi ${ }^{10}$, umutsuzluğun depresyon için yeterli bir sebep olduğunu ileri sürer. Olumsuz yaşam olayları karşısında, sabit, genel ve içsel sebeplere atıfta bulunan bir kişinin (örneğin bir kişisel nitelik ya da huya) umutsuz olması beklenmektedir. Bu umutsuzluk depresyonla sonuçlanır. Bir takım çalışmalar bu teoriyi desteklemektedir ${ }^{11}$.

Farklı bir çok inanç öğretisi, umutsuzluk durumları hakkında Tanrı' nın desteği ve mutlu son vaadi ile dolu hikayeler ve bölümler içerir. Dindar insanlar için inanç, umutsuz düşüncelere karşı koymada önemli bir rol oynayabilir. HIV pozitif olan dindar insanlar diğer dindar olmayan hastalara göre daha düşük düzeyde umutsuzluğa sahiptirler ${ }^{12}$. Klinik depresyonlu örneklemde, Young ve arkadaşları ${ }^{13}$, depresif değilken, dinle daha çok meşgul olanların daha az umutsuz olduklarını bulmuştur.

Bu çalışmada, klinik depresyon tanısı almış kişilerde, dini uygulamalar ve dini inancın etkisi açıklanmaya çalışılmıştır. Çalışmanın hipotezi, dini uygulamalar ve inancın, demografik değişkenlerin dışında, düşük düzey depresyon ve umutsuzluğun yordayıcısı olabileceğidir. Dinin umutsuzlukla olan ters ilişkilisi yoluyla, dini inanç ve uygulamaların dolaylı olarak depresyonla ilişkili olduğu hipotezini sınamak için path analizi kullanılmıştır.

depression. London: Tavistock; Melges, F. T., \& Bowlby, J. (1969). Types of hopelessness in psychopathological process. Archives of General Psychiatry, 20, 690-699.

9 Beck, A. T. (1967). A.g.e.; Beck, A. T. (1991). Cognitive therapy: A 30-year retrospective. American Psychologist, 46, 368-375.

10 Abramson, L. Y., Metalsky, G. I., \& Alloy, L. B. (1989). Hopelessness depression: A theorybased subtype of depression. Psychological Review, 96, 358-372.

11 Golin, S., Sweeney, P. D., \& Shaeffer, D. E. (1981). The causality of causal attributions in depression: A cross-lagged panel correlational analysis. Journal of Abnormal Psychology, 90, 14-22; McCranie, E. W., \& Riley, W. T. (1992). Hopelessness and persistence of depression in an inpatient sample. Cognitive Therapy and Research, 16, 699 -708; Metalsky, G. I., \& Joiner, T. E. Jr. (1992). Vulnerability to depressive symptomatology: A prospective test of the diathesisstress and causal mediation components of the hopelessness theory of depression. Journal of Personality and Social Psychology, 63, 667-675; Reno, R. M., \& Halaris, A. E. (1989). Dimension of depression: A comparative longitudinal study. Cognitive Therapy and Research, 13, 549-563.

12 Carson, V., Soeken, K. L., Shanty, J., \& Terry, L. (1990). Hope and spiritual well-being: Essentials for living with AIDS, Perspectives in Psychiatric Care, 26(2), 28-34.

13 Young, M. A., Fogg, L. F., Scheftner, W., Fawcett, J., Akiskal, H., \& Maser, J. (1996). Stable trait components of hopelessness: Baseline and sensitivity to depression. Journal of Abnormal Psychology, 105, 155- 165. 


\section{Yöntem}

Örneklem 196 kadın ve 75 erkek, üçüncü derece bakım sağlık merkezindeki yatan (\%44) ve ayaktan tedavi gören (\%56) psikiyatrik hastadan oluşmuştur. Denekler, kendi gittikleri psikiyatristlerden (yatarak tedavi görenler) veya psikiyatristler tarafından tanısı konmuş ve yapılandırılmış görüşmelerle uygulanmış (ayaktan tedavi görenler) DSM-III-R ${ }^{14}$ için Yapılandırılmış Klinik Görüşme (Structured Clinical Interview) üzerinden major depresyon ve bipolar depresyon için DSM- $4^{15}$ kriterlerini karşılamıştır. Genel sağlık durumu nedeniyle ruhsal bozukluk, delilik, kayıp yaşama, psikotik bozukluk, organik ruhsal bozukluk, borderline kişilik bozukluğu, geçmiş 12 ay süresi içinde madde kötüye kullanımı geçmişi veya halihazırda bir manik epizodu olan denekler örneklemin dışında tutulmuştur. Deneklerin \% 76'sı beyaz, \% 11'i Afrikan Amerikalı, \%8'i Latin Amerikalı ve \%5'i diğer ırklardandır. Kabul edilen din olarak da baskın olarak örneklemin \%76'sı Hıristiyan, \%7' si Yahudi ve \%14' ü hiçbir dine inanmayan kişilerdir.

Dini davranışı ölçmek için iki ölçek kullanılmıştır. İlk olarak, asla ya da hemen hemen hiç (1) ile haftada bir kereden fazla (6) arasında değerlendirilen 6'lı Likert ölçeği ile insanlara "ne sıklıkla dini tören ve ibadetlere katıldıklarını" sorarak ibadetlere katılım düzeyleri ölçülmüştür. İkinci olarak, bireysel dini uygulamaların sıklığını belirlemek için deneklere; "Dini törenlere katılmanın dışında, manevi (spiritüel) ya da dini uygulamalarla ne kadar zaman geçirirsiniz?" sorusu sorulmuştur. Cevap seçenekleri (1) Yılda bir ya da daha az, (2) Ayda bir, yılda bir kaç kez, (3) Haftada bir, ayda birkaç kez, (4) Günde birkaç kez, haftada birkaç kez şeklindedir.

Dini inanç; Dini Mutluluk Ölçeği (Religious Well- Being Scale- RBW) ve Manevi Mutluluk Ölçeği'nin (Spiritual Well-Being Scale-SWB ${ }^{16}$ ) bir alt ölçeği ile değerlendirilmiştir. SWB, 10 tanesi dini ifadelerin dışında yaşamın amacına ilişkin duyguları tanımlayan bir boyutu olan varoluşsal mutluluğu (Existential Well-Being) ölçen ve 10 tanesi de Tanrı ile olan ilişkideki mutluluğu tanımlayan bir boyutu yani dini mutluluğu (Religious Well-BeingRWB) ölçen maddelerden oluşan toplam 20 maddelik bir ölçektir. Dini Mutluluk Ölçeği, dini bir dile sahip olduğundan dolayı inancı ölçmek için

14 Spitzer, R. L. (1990). Structured clinical interview for DSM-III-R. Washington, DC: American Psychiatric Press.

15 American Psychiatric Association. (1994). Diagnostic and statistical manual of mental disorders (4th ed.). Washington, DC: Author.

16 Paloutzian, R. F., \& Ellison, C. W. (1982). Loneliness, spiritual well-being and the quality of life. In L. A. Peplau \& D. Perlman (Eds.), Loneliness: A sourcebook of current theory, research and therapy (pp. 224-236). New York: Wiley. 
kullanılmıştır. Ayrıca, Varoluşsal Mutluluk Ölçeği’ nin kişilik özellikleriyle ilişkili olduğu görünmektedir. Bu ilişki Dini Mutluluk Ölçeği' nde görülmemiştir ${ }^{17}$. Bu araştırmanın örnekleminde Dini Mutluluk Ölçeği ile Varoluşsal Mutluluk Ölçeği arasındaki korelasyon .58, p<.001 bulunmuştur. Dini Mutluluk Ölçeği "Tanrı'nın benim sorunlarımla ilgilendiğine inanıyorum” gibi ifadelerle, bireylerin Tanrı'yla ilişkileri hakkındaki inançları ile ilgili bilgi sağlamaktadır. Cevaplayıcıların Tanrı tanımlamalarını (1) Kesinlikle Katılmıyorum ve (6) Kesinlikle Katılıyorum dereceleri arasında puanlamaları için yönerge hazırlanmıştır. Alınacak puanlar 10 ile 60 arasındadır. Ölçekten alınan yüksek puan yüksek düzeyde dini mutluluğu gösterir. Bu örneklemde, Dini Mutluluk Ölçeği' nin güvenirlik katsayısı .93 bulunmuştur. Çalışmalar ölçeğin geçerliğini göstermektedir ${ }^{18}$.

Umutsuzluk, Beck, Weissman, Lester ve Trexler ${ }^{19}$ tarafindan geliştirilen, 20 maddelik, doğru- yanlış (Evet- Hayır) şeklinde puanlanan, umutsuzluk düzeyini gösteren bir kendini değerlendirme ölçeği olan Beck Umutsuzluk Ölçeği ile ölçülmüştür. Puan ranjı 0 ile 20 arasındadır. Ölçekten 20 puan almak yüksek düzeyde umutsuzluğu gösterir. Bu örneklemde ölçeğin güvenirlik katsayısı .90 dır. Umutsuzluk Ölçeği ile umutsuzluğun klinik oranları arasında genel örneklemde .74 ve intihara teşebbüs etmiş insanların oluşturduğu örneklemde .62 olarak bulunan korelasyonlar ölçeğin geçerliğine kanıt oluşturmaktadır ${ }^{20}$.

Beck ve arkadaşları ${ }^{21}$ tarafından geliştirilen Beck Depresyon Envanteri depresyon araştırmalarında yaygın olarak kullanılmaktadır. Bu ölçek 0 (semptomların en zayıf hali) ile 3 (semptomların en güçlü hali) arasında siralanan 21 adet kendini değerlendirme maddesiyle depresyonun derinliğini ölçmekte kullanılmaktadır. Bu araştırmanın ̈rnekleminde ölçeğin güvenirlik katsayıs1 .87 bulunmuştur. Beck, Steer ve Garbin ${ }^{22}$ ölçeğin psikometrik özellikleriyle ilgili esaslı bir kanıt sağlamıştır. Araştırmacılar, BDE ile diğer çeşitli depresyon ölçümleri arasında .55 ile .76 arasında bir korelasyon bildirmişlerdir.

17 Piedmont, R. L. (1999). Four strategies for using the five-factor model in religious research. Journal of Psychology and Theology, 27, 338-350.

18 Ellison, C. W. (1983). Spiritual well-being: Conceptualization and measurement. Journal of Psychology and Theology, 11, 330-340.

19 Beck, A. T., Weissman, A., Lester, D., \& Trexler, L. (1974). The measurement of pessimism: The Hopelessness Scale. Journal of Consulting and Clinical Psychology, 42, 861-865.

20 Beck, A. T., Weissman, A., Lester, D., \& Trexler, L. (1974). A.g.e.

21 Beck, A. T., Ward, C. H., Mendelson, M., Mock, J., \& Erbaugh, J. (1961). An inventory for measuring depression. Archives of General Psychiatry, 4, 53-63.

22 Beck, A. T., Steer, R., \& Garbin, M. (1988). Psychometric properties of the Beck Depression Inventory: Twenty-five years of evaluation. Clinical Psychology Review, 8, 77-110. 
Yatarak tedavi gören genel yetişkin psikiyatri ünitesine yeni girişlerle oluşan tablo, hastaların bu çalışmanın kriterlerini karşılayıp karşılamadıklarını belirlemek üzere gözden geçirilmiştir. Bu elemeden sonra, seçilebilir hastalar, araştırmanın bir parçası olmaları için davet edilmiştir. Örneklemin ayaktan tedavi edilen kısmı için, diğer depresyon çalışmasına dahil edilmek üzere seçilen hastalara "Bu çalışmaya katılmaya gönüllü olur musunuz?" diye sorulmuştur. Hastalar kendi formlarını kullanarak ölçekleri tamamlamışlardır.

\section{Sonuç ve Tartışma}

Tablo 1 de, kullanılan ölçeklerin betimleyici istatistikleri sunulmuştur. Bu örneklemin Dini Mutluluk Ölçeği puanlarının Fitchett, Burtan ve Sivan' in bildirdiğ ${ }^{23}$, diğer psikiyatri hastalarının puanlarından $(46,6)$ veya ayaktan tedavi görenlerin puanlarından $(52,4)$ daha düşük olduğu görünmektedir. Ortalama olarak, katılımcılar birkaç ayda bir ibadetlere katılmaktadır ve haftada bir bireysel dini uygulamalarda bulunmaktadırlar. Amerikalıların \%59'u en az ayda bir ibadet ettiklerini söylerken, \% 75 i her gün dua ettiklerini bildirmişlerdir ${ }^{24}$. Bu örneklemdeki umutsuzluk puanlamalarının ortalaması 10,8 dir. Bu ölçekten alınan 9 ve üstü puanlar intiharı yordayıcı olarak görülmektedir ${ }^{25}$. BDE' nin puan ortalaması cevaplayıcıları ağır depresyonla orta düzey arasında bir kategoriye yerleştirilmiştir (puanlar 19-29 arasında ${ }^{26}$ ).

Dini uygulamalar ve inancın depresyon ve umutsuzlukla ilişkisini açılamak için hiyerarşik regresyon analizi kullanılmıştır. İlk adımda demografik değişkenler eş zamanlı olarak girilmiştir. İkinci adımda dini değişkenler girilmiştir. Depresyon ve umutsuzluk için yapılan regresyon analizi Tablo 2 'de sunulmuştur. Dini değişkenler, demografik değişkenlerin açıkladığı varyansın dışında, depresyon ve umutsuzluğu yordamak için eklenmiştir. Bu değişkenlerden yalnızca "inancın" sonuçlarla anlamlı bir ilişki gösterdiği bulunmuştur. Diğer çalışmalarla tutarlı olarak, dini inanç daha düşük depresyonla ${ }^{27}$ ve düşük umutsuzluk ile ${ }^{28}$ ilişkilidir.

23 Fitchett, G., Burton, L. A., \& Sivan, A. B. (1997). The religious needs and resources of psychiatric inpatients. The Journal of Nervous and Mental Disease, 185, 320-326.

24 Gallup, G. H. (1996). Religion in America. Princeton, NJ: Princeton Religious Research Center.

25 Beck, A. T., Steer, R. A., Kovacs, M., \& Garrison, B. (1985). Hopelessness and eventual suicide: A 10-year prospective study of patients hospitalized with suicidal ideation. American Journal of Psychiatry, 145, 559- 563.

26 Beck, A. T., Steer, R., \& Garbin, M. (1988). A.g.e.

27 Maton, K. I. (1989). A.g.e.; Mclntosh, D. N., Silver, R. C., \& Wortman, C. B. (1993). A.g.e.; Pressman, P., Lyons, J. S., Larson, D. B., \& Strain, J. J. (1990). A.g.e.

28 Carson, V., Soeken, K. L., Shanty, J., \& Terry, L. (1990). A.g.e.; Young, M. A., Fogg, L. F., Scheftner, W., Fawcett, J., Akiskal, H., \& Maser, J. (1996). A.g.e. 
Depresyona eşlik eden enerji kaybı nedeniyle, ibadetlere katılmak ile psikolojik değişkenler arasında bir ilişki olmaması makul görünmektedir. Özel ibadetlerin anlamlı olmaması karşılıklı etki olasılığı ile açılanabilir. Stres zamanlarında insanların bireysel ibadetlere yöneldiği gösterilmiştir ${ }^{29}$; bu da dini davranış ile depresyon arasında bir ilişki olduğunu göstermiştir. Diğer taraftan, özel dindarlığın daha düşük depresyonla birlikte olabildiği ileri sürülmüştür ${ }^{30}$. Eğer her iki etki bu örneklemde görülmüşse, anlamsız bir ilişkiye yol açan bu etkiler birbirini dengelemiştir.

Tablo 1: Ölçümlerin Ham Puanları İçin Betimleyici İstatistikler

Ölçüm

Dini Mutluluk Ölçeği

İbadete Katılma

Özel Dini Uygulamalar

Umutsuzluk Ölçeği

Beck Depresyon Ölçeği

$\mathrm{N}=271$

\begin{tabular}{crrr} 
Ortalama & SD & \multicolumn{1}{c}{ Min* } & Max* $^{*}$ \\
\hline 36,4 & 14,3 & 10 & 60 \\
2,7 & 1,6 & 1 & 6 \\
2,4 & 1,3 & 1 & 4 \\
10,8 & 5,5 & 0 & 20 \\
27,1 & 10,6 & 2 & 57
\end{tabular}

* Gerçek minimum ve maksimum puanlar

Path analizi dolaylı ve dolaysız bileşenler içindeki ilişkileri ayrıştırmaya izin verir. Path analizi nedensellik sağlayamasa da, nedensel teorimizin verilerle tutarlı olup olmadığını değerlendirmemize izin vermektedir ${ }^{31}$. Bireysel uygulamalar ve katılımlar regresyon modelinde anlamlı çıkmadığı için, path analizine dahil edilmemiştir. Umutsuzluk ve depresyonun korelasyonlarının şişirilmesinden kaçınmak için, BDE nin umutsuzluk odaklı olan 2. maddesi çıkarılmıştır.

Path analizi, inancın $(-.32, \mathrm{p}<, 001)$ depresyon üzerindeki dolaylı etkisi ile, depresyonda dini inançların etkisine umutsuzluğun aracılık ettiği yönünde öne sürülen nedensel modeli desteklemiştir (Şekil 1). Bu, dini inancın depresyonu nasıl dengelediğine dair daha açık bir anlayış sunmaktadir.

\footnotetext{
29 Ellison, C. G. (1991). A.g.e.; Idler, E. L. (1987). A.g.e

30 Idler, E. L. (1987). A.g.e

31 Peyrot, M. (1996). Causal analysis: Theory and application. Journal of Pediatric Psychology, 21, 3-24.
} 
Tablo 2: Depresyon ve Umutsuzluk İçin Hiyerarşik Regresyon Analizi Sonucu

\begin{tabular}{|c|c|c|c|c|c|c|c|c|}
\hline \multirow[b]{3}{*}{ Grup } & \multicolumn{4}{|c|}{ Depresyon } & \multicolumn{4}{|c|}{ Umutsuzluk } \\
\hline & \multicolumn{2}{|c|}{ Adım 1} & \multicolumn{2}{|c|}{ Adım 2} & \multicolumn{2}{|c|}{ Adım 1} & \multicolumn{2}{|c|}{ Adim 2} \\
\hline & B & $\beta$ & B & $\beta$ & B & $\beta$ & B & $\beta$ \\
\hline Cinsiyet (a) & -4.34 & $-.18 * *$ & -4.35 & $-.18 * *$ & -0.77 & -.06 & - 1.17 & -.10 \\
\hline Irk (b) & 6.05 & $.24 * * *$ & 5.41 & $.22 * * *$ & 2.78 & $.21 * * *$ & 1.88 & $.15^{* *}$ \\
\hline Yaş (c) & -2.40 & $-.22 * *$ & -2.16 & $-.20 * *$ & -1.01 &,$- 18 *$ & -0.36 & -.06 \\
\hline Meslek & -3.84 & $-.18 * *$ & -3.98 & $-.19 * *$ & -0.39 & -.04 & -0.50 & -.05 \\
\hline Yalnız Yaşama & 3.33 & $.15 *$ & 3.35 & $.15^{*}$ & 1.70 & $.14 *$ & 1.15 & .10 \\
\hline Evli & 4.27 & $.19 * *$ & 4.37 & $.20 * *$ & 0.33 & .03 & 0.46 & .04 \\
\hline Eğitim Düzeyi & 0.07 & .01 & -0.06 & -.01 & 0.28 & .06 & 0,12 & .03 \\
\hline Dini İnançlar & & & $-0,16$ & $-.22 * *$ & & & -0.18 & $.45 * * *$ \\
\hline İbadet etme (c) & & & 1,05 & .05 & & & -0.02 & .00 \\
\hline \multirow[t]{2}{*}{ Özel Uygulamalar } & & & 0.86 & .10 & & & 0.17 & .04 \\
\hline & \multicolumn{4}{|c|}{ Intercept $=42,83$} & \multicolumn{4}{|c|}{ Intercept $=17,51$} \\
\hline $\mathrm{R}^{2}\left(? \mathrm{R}^{2}\right)$ & & 186 & 211 & 025) & & & 258 & 16) \\
\hline F değeri anlamlılı̆̆ & & ,000 & ,044 & & & 00 & ,000 & \\
\hline
\end{tabular}

$\mathrm{N}=271$

(a) Erkek $=1$. (b) Beyaz $=1$. (c) değişkenin karekökü.

$* \mathrm{p}<.05 \quad * * \mathrm{p}<, 01 \quad * * * \mathrm{p}<, 001$



Şekil 1: Dini İnancın Umutsuzluk ve Depresyonla İlişkisinin Standardize Edilmiş Katsayılarıyla Path Modeli

Path analizi, depresyonla ilişkili dini inançların rolünün karmaşıklığını ortaya çıkarmıştır. Dini inanç ile depresyon arasındaki pozitif ilişki, güçlü inançlara sahip bazı insanların böylesi inançlara sahip olmayanlardan daha fazla depresif olduklarını desteklemektedir. Bulguları yorumlamak için muhtemel iki açıklama vardır. Birinci açıklama, depresyonun, rehabilitasyon 
amaçlı yatan hastalarda ${ }^{32}$ ve olumsuz yaşam olaylarını deneyimleyen kişilerde olduğu gibi ${ }^{33}$, teselli bulmak için dine yönelmeyle ortaya çıkan, dini inanç ve uygulamalardaki yoğunlaşmanın bir sonucu olabileceğidir. Depresyondaki ve hastaneye yatışlardaki yükseliş bazı insanların baş etmek için dine yönelmesi ile sonuçlanabilir. Böyle bir durumda din yalnızca depresyonu etkilemez, depresyon da insanların daha güçlü dini inançlara sahip olmasina neden olur.

Bazı dini inanç ve uygulamaların depresyona katkıda bulunabileceği fikri de alternatif bir açıklamadır. Pargament ve arkadaşları ${ }^{34}$ Tanrı tarafından cezalandırıldığını ya da şeytanın kontrolünde olduğu şeklindeki inançları içeren başa çıkma modelinin bu etkisine dikkat çekmiştir.

Araştırmanın sınırlılıklarından biri kullanılan dini ölçeklerde bulunmaktadır. Özellikle, Manevi (Spiritüel) Mutluluk Ölçeği Hıristiyan kolej öğrencilerinde kullanılmak için geliştirilmiştir ve daha farklı dindar örneklem için uygun bir ölçek olmayabilir. Maddeler kişisel Tanrı inancını yansıttığından tüm gruplar için uygun değildir. Gelecek çalışmalarda amaç; daha kapsamlı dini ölçekler geliştirmek ve kullanmak olmalıdır. İbadete katılma ve bireysel dua etme ölçekleri farklı gelenekler için farklı ayrıntıları içermelidir.

Bu araştırmada dinin olumlu bir halini ve Tanrı' yla destekleyici bir ilişkiyi ölçen araçlar kullanılmıştır. Young ve arkadaşlarına göre ${ }^{35}$ çalışmalar özel (spesifik) dini inançları açılamaya ihtiyaç duymaktadır. Her ne kadar bu araştırma bu konuya dikkat çekse de, günah hakkındaki öğretiler ve olumsuz Tanrı imgeleri gibi, depresyon veya umutsuzluğu artırabilen inançları ölçmemiştir. Bu, gelecekte yapılacak bir araştırmanın konusudur.

Bu araştırmada kullanılan dini ölçekler Tanrı ile ilişkiyi ölçtüğü için, belki sonuçlar sadece, diğerleriyle iyi ilişkileri olan bireylerde bulunan kişilik özelliklerini yansıtmaktadır. Örneğin, Young ve arkadaşları (1996) regresyon analizlerinde Eysenck Dışadönüklük Ölçeği puanlarının düşük düzey umutsuzlukla ilişkili olduğunu bulmuşlardır. Eğer dindarlık dışadönüklükle ilişkili olsaydı, o zaman din ve umutsuzluk arasındaki ilişki sahte olabilirdi. Yine de, Piedmont, Dini Mutluluk Ölçeği ile Dışadönüklük Ölçe-

32 Fitchett, G., Rybarczyk, B. D., DeMarco, G. A., and Nicholas, J. J. (1999). The role of religion in medical rehabilitation outcomes: A longitudinal study. Rehabilitation Psychology, 44, 333353.

33 Ellison, C. G. (1991). A.g.e.

34 Pargament, K. I., Smith, B. W., Koenig, H. G., \& Perez, L. (1998). Positive and negative religious coping with major life stressors. Journal for the Scientific Study of Religion, 37, 710-724.

35 Young, M. A., Fogg, L. F., Scheftner, W., Fawcett, J., Akiskal, H., \& Maser, J. (1996). A.g.e. 
ği arasında bir ilişki bulamamıştır ${ }^{36}$ ve NEO Kişilik Envanterinin (NEO Personality Inventory) Nörotisizm Ölçeği arasında bir ilişki bulunamamıştır. Bununla birlikte, ilerde yapılacak çalışmalarda, bu boyutun ötesinde, kişiliği açıklamak için, dini inanç ve uygulamaların katkısının incelenmesi önemli olacaktır.

Psikolojik ölçeklerle ilgili de bir sınırlılık vardır. Hem Umutsuzluk Ölçeği hem de Beck Depresyon Ölçeği kendini değerlendirme ölçekleridir ve önyargılı cevaplara açıktır. Bu bazı düşük BDE ve BUÖ puanlarını açıklayabilir. Sosyal istenilirliği test eden maddeleri içermesi yararlı olabilir. Bizim hipotezimiz, dini inancın umutsuzluğa neden olan olumsuz atıfların yerini alabileceğidir. Savımızı desteklemek için özellikle atıfları ölçen bir araca ihtiyaç duyulmaktadır.

Her ne kadar bizim araştırmamız, önerilen nedensel modelin verilerle tutarlı olduğunu gösterse de kesitsel dizayn (Cross-Sectional Design) sebep ve etkinin açık bir işaretine müsaade etmemektedir. Düşük düzeydeki dini inanç; depresyon ve umutsuzluğun sebebi olabilir. Boylamsal bir analiz, nedensel durumu saptamak için gösterilen çabaları geliştirebilir.

Bir inanç sistemine sahip hastalar için, bu inançlarını terapiye dahil etmek umutsuzluk ve depresyonu önleyebilir ya da azaltabilir. Dini inanç, dindar bir insana bilişsel bir çatı sağlar. Sonuçlar, dini inancın etkili bir şeklinin umutsuzluğa karşı olan inançları kendine çekmek olduğunu açıkça göstermiştir. Dinle depresyon arasındaki pozitif ilişki de dindar insanlarda muhtemel dini problemlerin gizlendiğinin önemine işaret eder.

Depresyon semptomları için dinin terapiye dahil edilmesinin, terapist dindar olmasa bile, dindar insanlarda standart bilişsel davranışsal yöntemlerden daha fazla etkili olabildiğine dair bazı kanıtlar vardır ${ }^{37}$. Dini inanç ile umutsuzluk ve depresyon arasındaki nihai nedensel ilişki ne olursa olsun, bu çalışma, dini inanç ve duygusal iyiliğin bağlantısını gösteren delilleri desteklemekte ve kullanılan bu klinik kaynakların potansiyel yararlarına işaret etmektedir. Bazı bireyler için zararlı olabilen dini inançları dikkate almaya ihtiyaç duyulduğunun daha çok farkına varılmaktadır.

36 Piedmont, R. L. (1999). A.g.e.

37 Propst, R., Ostrom, R., Watkins, P., Dean, T., \& Mashburn, D. (1992). Comparative efficacy of religious and nonreligious cognitivebehavioral therapy for the treatment of clinical depression in religious individuals. Journal of Consulting and Clinical Psychology, 60, 94-103. 